\title{
TCO, a Putative Transcriptional Regulator in Arabidopsis, Is a Target of the Protein Kinase CK2
}

\author{
Laina M. Weinman ${ }^{1}$, Katherine L. D. Running ${ }^{1}{ }^{\circledR}$, Nicholas S. Carey ${ }^{1}$, Erica J. Stevenson ${ }^{2}$, \\ Danielle L. Swaney ${ }^{2,3}$, Brenda Y. Chow ${ }^{1}$, Nevan J. Krogan ${ }^{2,3}$ and Naden T. Krogan ${ }^{1, *(D)}$ \\ 1 Department of Biology, American University, 4400 Massachusetts Avenue NW, Washington, DC 20016, USA; \\ laina.weinman@alumni.american.edu (L.M.W.); katherine.running@ndsu.edu (K.L.D.R.); \\ nc7356a@student.american.edu (N.S.C.); bchow@american.edu (B.Y.C.) \\ 2 Gladstone Institute of Data Science and Biotechnology, J. David Gladstone Institutes, \\ San Francisco, CA 94158, USA; erica.stevenson@gladstone.ucsf.edu (E.J.S.); \\ danielle.swaney@ucsf.edu (D.L.S.); nevan.krogan@ucsf.edu (N.J.K.) \\ 3 Quantitative Biosciences Institute (QBI), University of California, San Francisco, CA 94158, USA \\ * Correspondence: nkrogan@american.edu; Tel.: +1-202-885-2203
}

Received: 7 November 2018; Accepted: 26 December 2018; Published: 28 December 2018

\begin{abstract}
As multicellular organisms grow, spatial and temporal patterns of gene expression are strictly regulated to ensure that developmental programs are invoked at appropriate stages. In this work, we describe a putative transcriptional regulator in Arabidopsis, TACO LEAF (TCO), whose overexpression results in the ectopic activation of reproductive genes during vegetative growth. Isolated as an activation-tagged allele, tco-1D displays gene misexpression and phenotypic abnormalities, such as curled leaves and early flowering, characteristic of chromatin regulatory mutants. A role for TCO in this mode of transcriptional regulation is further supported by the subnuclear accumulation patterns of TCO protein and genetic interactions between $t c o-1 D$ and chromatin modifier mutants. The endogenous expression pattern of TCO and gene misregulation in tco loss-of-function mutants indicate that this factor is involved in seed development. We also demonstrate that specific serine residues of TCO protein are targeted by the ubiquitous kinase CK2. Collectively, these results identify TCO as a novel regulator of gene expression whose activity is likely influenced by phosphorylation, as is the case with many chromatin regulators.
\end{abstract}

Keywords: Arabidopsis thaliana; chromatin regulation; CK2; development; phosphorylation; protein kinase; transcriptional regulation

\section{Introduction}

Growth and development in multicellular eukaryotes involves the integration of diverse cell types whose specification is under strict spatial and temporal control. This fate specification is the product of precise gene expression patterns established through a balance between transcriptional activation and repression. On a broad scale, this balance ensures that developmental programs are invoked at appropriate stages in an organism's life cycle. While eukaryotes employ many mechanisms to mediate this control, chromatin modification is especially well-suited to establish and sustain a particular transcriptional state. For example, Polycomb group (PcG) and Trithorax group (trxG) proteins are chromatin modifiers that play critical roles by stably repressing or activating transcription, respectively. Two important PCG multi-protein complexes include PRC2, which trimethylates histone H3K27, and PRC1, which ubiquitylates histone H2A to compact chromatin and silence gene expression [1]. Conversely, trxG proteins antagonize PcG repression through mechanisms that include trimethylation of histone H3K4 and ATP-dependent chromatin remodeling [1]. 
In higher plants, reproductive flowers arise late in development, with floral-specific genes being repressed throughout vegetative growth. In the model angiosperm Arabidopsis thaliana, chromatin modifiers are key to this repression, as their mutation results in ectopic gene expression and numerous developmental defects. For example, mutation of the histone methyltransferase CURLY LEAF (CLF), a PRC2 component, causes derepression of floral organ genes and results in upward-curled leaves, small rosettes, early flowering, short inflorescence stems, and homeotic conversions of floral organs [2]. Antagonizing CLF function are trxG factors such as ARABIDOPSIS HOMOLOG OF TRITHORAX1 (ATX1) and ULTRAPETALA1 (ULT1), mutations of which suppress clf defects [3,4]. Consistent with this antagonistic relationship, Arabidopsis plants overexpressing ULT1 display similar phenotypic abnormalities as clf loss-of-function mutants [4]. Apart from floral organ gene repression, different Arabidopsis PRC2 complexes control diverse growth programs, ranging from endosperm and seed development to vernalization-dependent floral transition [5].

Since organismal growth programs can be strongly influenced by dynamic internal and external cues, they are often plastic in nature [6,7]. It follows that the chromatin regulation underlying these processes is similarly flexible. Post-translational protein modification is an effective strategy for conferring such plasticity, and chromatin regulators are commonly subject to these modifications, including phosphorylation [8]. Phosphorylation can influence many protein properties such as subcellular localization, enzymatic activity, protein-protein interactions, and chromatin association [9]. For example, phosphorylation of the PRC2 methyltransferase Enhancer of Zeste homolog 2 (EZH2) prevents histone binding and compromises its catalytic activity, resulting in gene derepression [10]. Human orthologs of the trxG SNF/SWI complex are also phosphorylated during mitosis, resulting in their exclusion from chromatin [11].

Phosphorylated chromatin modifiers often harbor kinase recognition sequences that are acidic in nature, implicating casein kinase 2 (CK2), a ubiquitous Ser/Thr protein kinase, as a prevalent regulator [8]. Indeed, the Drosophila PRC2 component Extra sex combs (Esc) and its mammalian ortholog Embryonic Ectoderm Development (EED) are phosphorylated by CK2, which promotes protein homodimerization and influences overall complex formation [12,13]. Similarly, CK2-mediated phosphorylation of the PRC1 subunit $\mathrm{Cbx} 2$ in mouse changes its binding affinity for modified histone H3 [14].

In the present work, we describe the isolation of an activation-tagged mutant in Arabidopsis we named taco leaf-1D (tco-1D) due to its strongly upward-curled leaves. Numerous properties of tco-1D are consistent with disrupted chromatin regulation, including its developmental abnormalities, misregulated genes, and genetic interactions with mutants of PcG and trxG homologs. Additionally, the nuclear localization of TCO often displays a "speckled" distribution reminiscent of numerous eukaryotic chromatin regulators. The expression pattern of TCO and defects associated with tco loss-of-function mutants implicate this factor in the regulation of seed development. Finally, TCO is bound and phosphorylated by CK2, suggesting that a posttranslational regulatory mechanism broadly used to control the activity of chromatin modifiers may also influence TCO function.

\section{Results}

\subsection{Identification and Characterization of the Leaf-Curling Mutant Taco Leaf-1D}

To identify novel genes involved in lateral organ patterning, we performed an activation-tagging mutant screen in Arabidopsis. We isolated one dominant mutant that exhibited strong upward leaf curling (Figure 1A-D) that we named taco leaf-1D (tco-1D). Apart from this leaf-curling defect, which affected both rosette and cauline leaves (Figure 1B,D,F), tco-1D flowered earlier than wild type based on the number of rosette leaves initiated prior to the floral transition (Figure 1G). The leaves and inflorescence stems of tco-1D were also shorter than those of the wild type (Figure 1H,I), giving the mutant a highly compact stature (Figure 1E) with a reduced number of siliques (Figure 1J). 

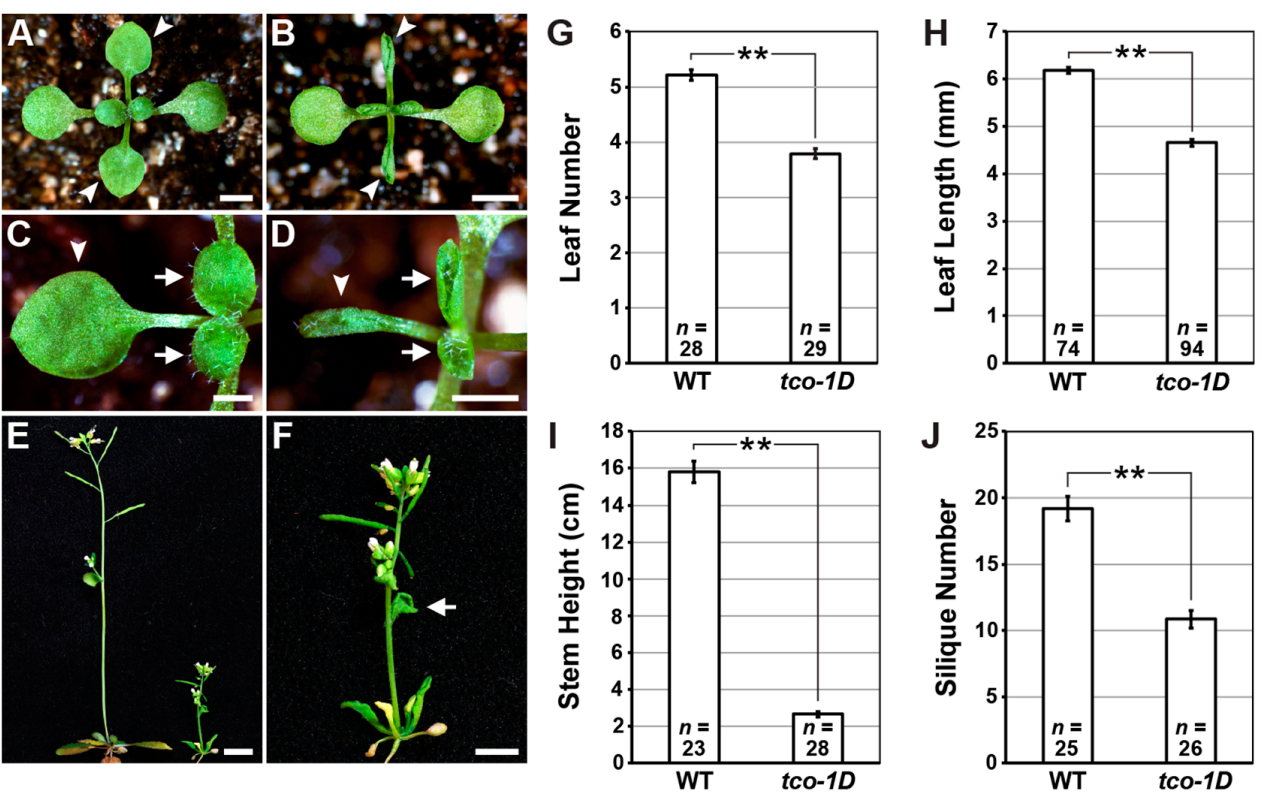

Figure 1. The activation-tagged mutant tco- $1 D$ has dominant, pleiotropic effects on Arabidopsis growth and development. (A-D) 14 days after germination (DAG) plants of wild type (A,C) and tco-1D (B,D). Arrowheads denote first pair of vegetative leaves, while arrows indicate the third and fourth leaves. Note strong upward curling displayed by tco-1D leaves. (E) 40 DAG plants of wild type (left) and tco-1D (right). (F) Higher magnification of tco-1D plant depicted in (E), with arrow denoting upward-curled cauline leaf. Bars: (A,B) $2 \mathrm{~mm}$; (C,D) $1 \mathrm{~mm}$; (E) $1 \mathrm{~cm}$; (F) $5 \mathrm{~mm}$. (G-J) Phenotypic comparisons between wild type (WT) and tco-1D. Number of vegetative leaves initiated prior to flowering $(\mathbf{G})$, length of first vegetative leaves at 16 DAG $(\mathbf{H})$, primary inflorescence stem height at 65 DAG (I), and number of siliques produced by the primary inflorescence stem $(\mathbf{J})$ are shown. Data are represented as mean $+/$ - standard error (SE). Statistically significant differences are indicated (** $p<0.001$; two-tailed $t$-test). Sample size $(n)$ of each genotype is provided.

Using a thermal asymmetric interlaced (TAIL) polymerase chain reaction (PCR)-based approach [15], we determined that the activation-tagging T-DNA in tco-1D resides between genes At4g23110 and At4g23120 in the Arabidopsis genome, with the tandemly repeated 2x35S CaMV enhancers of the T-DNA oriented towards At4g23110 (Figure 2A). When semi-quantitative reverse transcription-PCR (RT-PCR) was used to test At4g23120 transcript levels in tco-1D and wild-type seedling tissue, expression could not be detected in either background, despite efficient PCR amplification using the same primers and genomic DNA as template (Figure 2B). Expression of At4g23110 was also undetectable in wild-type seedling tissue; however, transcription of this gene was clearly upregulated in tco-1D (Figure $2 \mathrm{~B}$ ). These results were verified by quantitative RT-PCR, which showed that $A t 4 g 23110$ was ectopically expressed in tco- $1 D$ vegetative tissues in a reliable and reproducible fashion, while $A t 4 g 23120$ was not (Figure S1A-C). Collectively, these observations implicate $A t 4 g 23110$ as the activation-tagged locus in tco-1D.

To verify this prediction, we used the constitutive 2x35S CaMV promoter to drive expression of an At4g23110-GFP translational fusion (2x35Sp::TCO-GFP) and found that this transgene phenocopied tco-1D (Figure 2C,D,H). Therefore, we conclude that the identity of the TCO gene is At4g23110, which encodes a small (148 amino acid) protein sharing some homology with animal insulin-like growth factor binding proteins (as annotated by TAIR (www.arabidopsis.org)) [16]. BLAST alignment searches (www.ncbi.nlm.nih.gov/blast) [17] of other plant genomes identified proteins similar to TCO/At4g23110 in other Brassicaceae species, including Arabidopsis lyrata, Capsella rubella, Camelina sativa, Eutrema salsugineum, Raphanus satvius and Brassica napus (Figure S2A-D).

To gain insight into the function of TCO, we transiently expressed 2x35Sp::TCO-GFP in tobacco leaves to determine its subcellular localization. TCO protein localized to the nucleus, including 
in a subcellular compartment that resembled the nucleolus (Figure 2E-G). Bright TCO-GFP foci or "speckles" were also apparent in some nuclei (Figure 2G). Expression of 2x35Sp::TCO-GFP in stable Arabidopsis transformants also displayed punctate subcellular accumulation patterns consistent with nuclear localization (Figure S3A-F). These results indicate that TCO may function in transcriptional regulation and that the pleiotropic defects of $t c o-1 D$ may result from widespread gene misexpression.

A
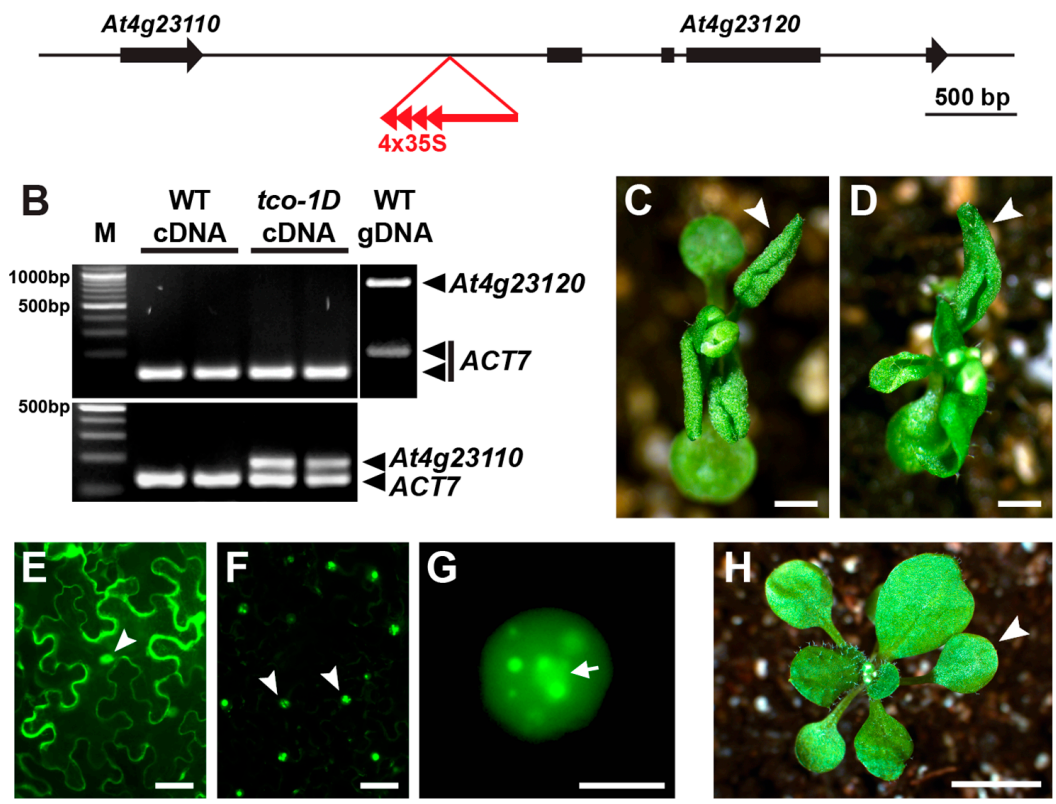

Figure 2. The Arabidopsis gene At4g23110 is overexpressed by the activation-tagging T-DNA in tco-1D. (A) Schematic showing the insertion site of the activation-tagging T-DNA (red) in tco-1D between genes $A t 4 g 23110$ and $A t 4 g 23120$. The 35S enhancer elements (red arrowheads) are oriented upstream. Gene exons are depicted as black rectangles, with black arrowheads showing gene orientation. (B) Semi-quantitative reverse transcription-polymerase chain reaction (RT-PCR) assessing the expression of genes $A t 4 g 23110$ (bottom) and $A t 4 g 23120$ (top) in 7 days after germination (DAG) seedlings of tco-1D and wild-type (WT), with ACTIN7 (ACT7) serving as an internal control. Two biological replicates of each RT-PCR reaction are shown. A PCR with WT genomic DNA shows efficient amplification of At4g23120 (top, right). (C) tco-1D and (D) 2x35Sp::TCO-GFP plants at 19 days after germination (DAG). Note similar curling of first vegetative leaves (arrowheads). (E-G) Transient transfections of tobacco leaves. (E) 2x35Sp::YFP is localized to the cell nucleus (arrowhead) and cytoplasm. (F) 2x35Sp::TCO-GFP localizes to nuclei (arrowheads). (G) Close-up of 2x35Sp::TCO-GFP nucleus showing localization in a central subnuclear compartment predicted to be nucleolus (arrow) and in other punctate nuclear foci. (H) WT plant at 19 DAG with first vegetative leaf denoted (arrowhead). Bars: (C,D) 1 mm; (E,F) $50 \mu \mathrm{m}$; (G) $10 \mu \mathrm{m}$; (H) $5 \mathrm{~mm}$.

\subsection{Reproductive Genes Are Ectopically Expressed in tco-1D Vegetative Tissues}

Short, upward-curled leaves and early flowering in Arabidopsis can result from ectopic expression of floral genes in vegetative tissues [2]. To test whether floral gene misregulation contributes to tco-1D developmental defects, we first crossed tco-1D to agamous (ag), a C-class floral organ identity gene as defined by the ABC model of floral patterning [18,19]. The rosette leaves of tco-1D ag-1 double mutants were less curled and significantly longer than those of tco-1D alone (Figure 3A-E), suggesting that ectopic $A G$ expression contributes to tco-1D developmental abnormalities. Consistent with this, quantitative RT-PCR confirmed that $A G$ is upregulated approximately 6-fold in tco-1D seedling tissue compared to that of wild type (Figure 3F; Figure S4C).

The incomplete suppression of $t c o-1 D$ by ag indicates that other genes are likely misexpressed in this background as well. To test this hypothesis, we assessed the expression levels of other floral 
patterning and/or flowering time genes (Figure 3F; Figure S4A-D), many of which result in leaf curling and/or early flowering when misregulated [20-29]. Numerous MADS-box floral organ identity genes were upregulated 2-fold or greater in tco-1D, including the A-class gene APETALA1 (AP1), the B-class genes AP3 and PISTILLATA (PI), the D-class genes ARABIDOPSIS B SISTER (ABS), SHATTERPROOF2 (SHP2) and SEEDSTICK (STK), and the E-class gene SEPALLATA3 (SEP3) (Figure 3F; Figure S4A-D). Conversely, the expression of the D-class gene SHP1 was not appreciably altered, indicating that the effect of $t c o-1 D$ on floral MADS-box genes displays some specificity. Further, the floral meristem identity gene LEAFY (LFY) and the flowering time gene FLOWERING LOCUS T (FT) did not show increased expression levels (Figure 3F; Figure S4A,C). This latter observation suggests that the early flowering of $t c o-1 D$ is not a product of $F T$ upregulation, but may be due to the upregulation of floral organ identity genes such as SEP3 [26]. Collectively, these results show that the tco-1D mutation leads to the ectopic expression of numerous floral organ identity genes, and that at least some of this gene misregulation contributes to tco-1D developmental defects. Along with its nuclear localization, these observations are consistent with TCO playing a role in the control of gene expression.
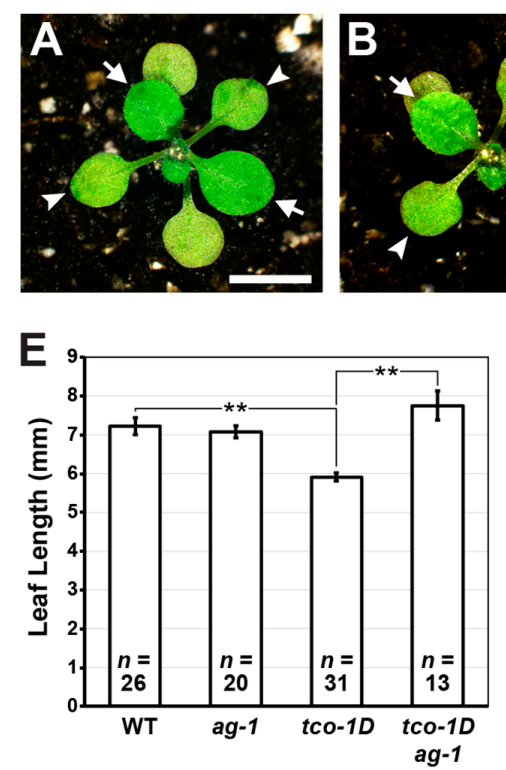
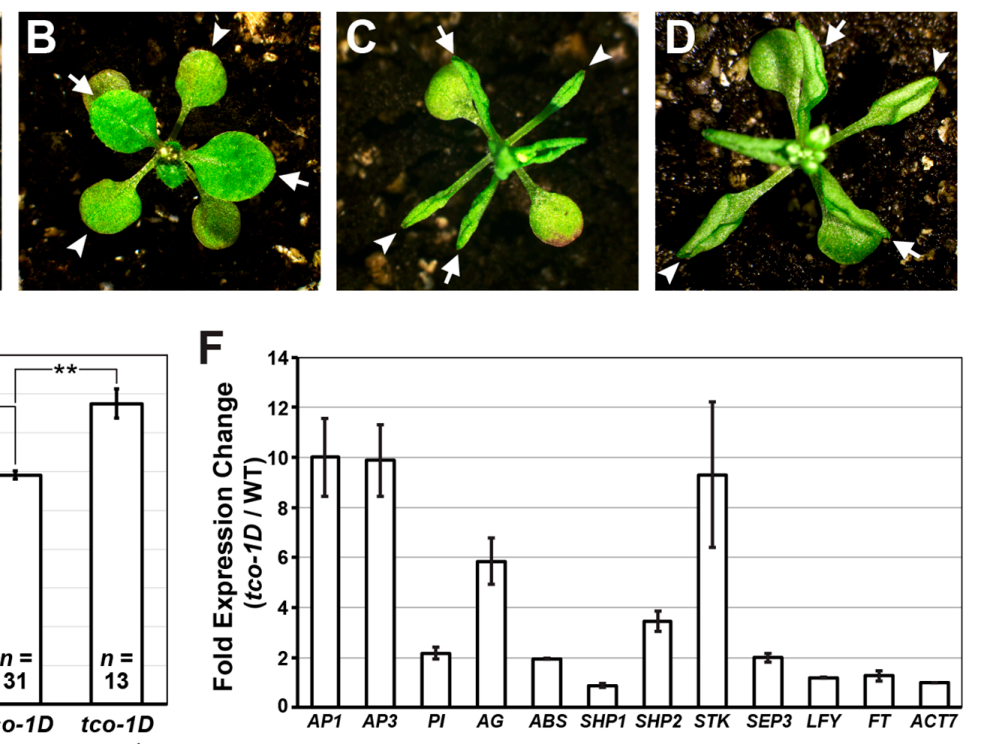

Figure 3. Developmental defects of $t c o-1 D$ are associated with misregulation of multiple floral organ identity genes in Arabidopsis. (A-D) 20 days after germination (DAG) plants of wild type (A), ag-1 (B), tco-1D (C) and tco-1D ag-1 (D). Arrowheads denote first pair of vegetative leaves, while arrows indicate third and fourth leaves. Bars: $5 \mathrm{~mm}$. (E) Length of third/fourth vegetative leaves of wild type (WT), ag-1, tco-1D and tco-1D ag-1 plants. Data are represented as mean $+/-\mathrm{SE}$. Asterisks denote statistically significant differences $(* * p<0.001$; two-tailed t-test). Sample size $(n)$ of each genotype is given. (F) Quantitative RT-PCR on genes controlling floral organ identity, floral meristem identity and flowering time in tco-1D seedlings (7 DAG) relative to wild type (WT). Assessed genes are APETALA1 (AP1), APETALA3 (AP3), PISTILLATA (PI), AGAMOUS (AG), ARABIDOPSIS B SISTER (ABS), SHATTERPROOF1 (SHP1), SHATTERPROOF2 (SHP2), SEEDSTICK (STK), SEPALLATA3 (SEP3), LEAFY (LFY), and FLOWERING LOCUS T (FT). Fold expression change (tco-1D/WT) was normalized against ACTIN7 (ACT7) expression. Data are represented as mean +/ - SE of two biological replicates. Primer sequences are provided in Table S1.

\subsection{TCO Displays Characteristics of a Chromatin Regulator}

TCO protein often accumulates in punctate subnuclear foci or "speckles" (Figure 2F,G), which is reminiscent of numerous chromatin-modifying proteins in both animals and plants [4,30-33]. This localization pattern suggests that TCO may influence gene expression through chromatin regulation. Indeed, the developmental defects and gene misregulation exhibited by tco-1D closely 
resembles those of PcG loss-of-function mutants (clf) and trxG overexpression lines (35Sp::ULT1) [2,4]. This includes upward-curled leaves, small rosettes, early flowering, short inflorescence stems that terminate growth prematurely, and ectopic expression of floral organ identity genes including $A G$, AP3 and SEP3 [2,4]. Moreover, ULT1 has been reported to exhibit a speckled subnuclear distribution pattern similar to that displayed by TCO [4].

If TCO influences transcription via chromatin regulation, the developmental defects of tco-1D may be enhanced by mutation of CLF and/or suppressed by mutation of ULT1, which is known to antagonize CLF activity in Arabidopsis [4]. As a first test of this hypothesis, we crossed tco-1D with $c l f-2$ to test for genetic interaction. Cotyledons of tco-1D mutants display increased angles of upward growth compared to wild-type cotyledons (Figure 4A,B). This hyponastic response was markedly enhanced in the $t c o-1 D$ clf-2 double mutant, which produced cotyledons that commonly bent over the top of the seedling to completely enclose newly initiated vegetative leaves (Figure $4 \mathrm{C}, \mathrm{D})$ ). Furthermore, $t c o-1 D$ clf-2 seedlings displayed tightly curled leaves that were significantly shorter than either single mutant (Figure 4E-H,K). Conversely, the phenotypic null allele ult1-2 [34] partially suppressed tco-1D leaf defects, as the tco-1D ult1-2 double mutant leaves were less tightly curled and significantly longer than tco-1D leaves (Figure 4F,I-K). Similar results were obtained from crosses between the semi-dominant allele ult1-1 [34] and tco-1D (Figure S5A-D). Taken together, these genetic interactions suggest that TCO plays a role in chromatin regulation, potentially by interacting with or influencing the activity of PcG and/or trxG homologs in Arabidopsis.
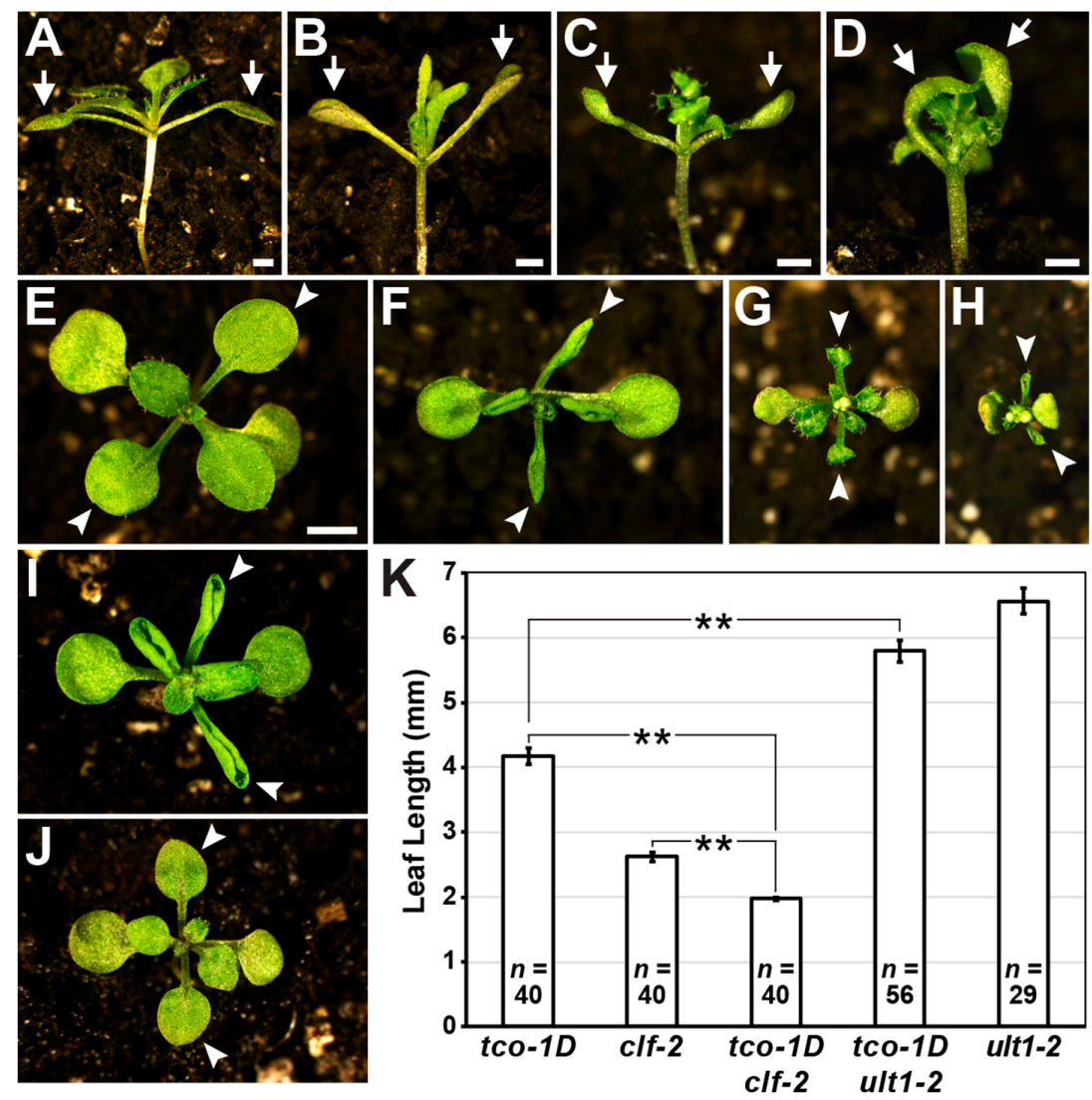

Figure 4. Vegetative defects of $t c o-1 D$ are enhanced by $c l f$ and suppressed by $u l t 1$. (A-D) Lateral views of 17 days after germination (DAG) wild type (WT) (A), tco-1D (B), clf-2 (C) and tco-1D clf-2 (D) plants, with cotyledons denoted (arrows). (E-J) Apical views of 17 DAG WT (E), tco-1D (F), clf-2 (G), tco-1D clf-2 (H), tco-1D ult1-2 (I) and ult1-2 (J) plants, with first vegetative leaves denoted (arrowheads). Bars: (A-D) $1 \mathrm{~mm}$; (E-J) $2 \mathrm{~mm}$. (K) Lengths of first vegetative leaves of tco-1D, clf-2, tco-1D clf-2, tco-1D ult1-2 and ult1-2 are shown. Data are represented as mean $+/-$ SE. Asterisks denote statistically significant differences $(* * p<0.001$; two-tailed $t$-test). Sample size $(n)$ of each genotype is provided. 


\subsection{TCO Exhibits Seed-Specific Expression}

To determine the endogenous TCO expression pattern, we generated a TCOp::TCO-GUS reporter transgene under the regulatory control of $2.4 \mathrm{~kb}$ and $1.6 \mathrm{~kb}$ of upstream and downstream TCO non-coding sequence, respectively. Consistent with our inability to detect expression of TCO in vegetative tissues (Figure 2B), previous transcriptomic analyses indicated that At4g23110 expression was seed-specific [35]; therefore, we concentrated our reporter analyses on this stage. Multiple independent transgenic TCOp::TCO-GUS lines showed expression throughout the seed, including in the seedcoat, endosperm and developing embryo (Figure 5A,B), suggesting a role for TCO in seed and/or embryo development.
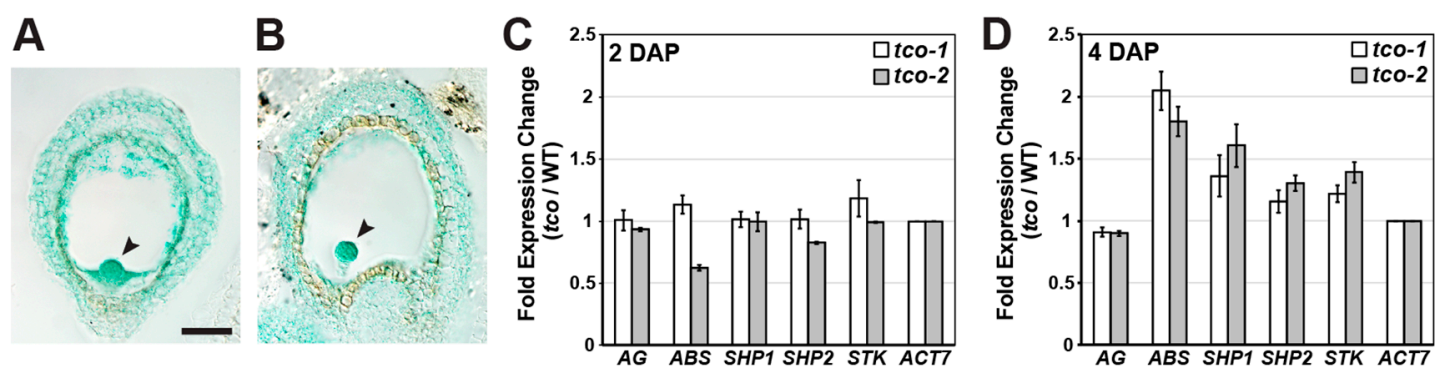

Figure 5. TCO is expressed throughout the Arabidopsis seed where it affects MADS-box gene expression. (A,B) Expression of TCOp::TCO-GUS in seeds of two independent transgenic lines of Arabidopsis. Note expression throughout the seed coat, endosperm and globular stage embryos (arrowheads). Bars: $50 \mu \mathrm{m}$. (C,D) Quantitative RT-PCR on C-class (AG) and D-class genes (ABS, SHP1, SHP2, STK) in tco-1 and $t c o-2$ siliques relative to wild type (WT) at 2 days after pollination (DAP) (C) and 4 DAP (D). Fold expression change (tco/WT) was normalized against ACTIN7 (ACT7) expression. Data are represented as mean $+/-$ SE of two biological replicates.

To test whether such stages were affected by loss of TCO function, we analyzed two T-DNA insertion mutants that interrupted the TCO coding region (Figure S6A). Unlike wild type, in both insertion lines (designated tco- 1 and $t c o-2$ ), full-length TCO transcripts were undetectable in silique tissue shortly after pollination, as assessed by RT-PCR using primers spanning the T-DNA insertion sites (Figure S6B). Furthermore, because both T-DNA insertions are positioned in the $5^{\prime}$ half of the TCO coding sequence (Figure S6A), it is unlikely that either allele produces functional TCO protein. Because multiple seed genes were ectopically expressed in $t c o-1 D$, we tested whether similar gene misregulation was apparent in tco silique tissue. At 2 days after pollination (DAP), the expression of Cand D-class MADS-box seed genes in the insertion lines was similar to wild type (Figure 5C). However, at $4 \mathrm{DAP}$, both insertion lines displayed an increase in the expression of the D-class gene $A B S$, and subtle increases in other D-class genes (Figure 5D).

Consistent with a role for TCO in seed development, tco- 1 also displayed seed defects at incomplete penetrance. Specifically, at $9 \mathrm{DAP}$, a proportion of seeds in $t c o-1$ siliques were white-to-light green in coloration $(32.1 \%, n=661)$ (Figure S7A-D). Tissue dissections revealed that these light-colored seeds harbored embryos at the globular stage, while their dark-colored siblings contained bent-cotyledon stage embryos, as did wild-type seeds of the same age (Figure S7E-L). In comparison, tco-2 exhibited seed defects at a much lower frequency $(1.9 \%, n=647)$ which was comparable to the wild type $(1.2 \%$, $n=1705$ ). Although both tco insertions affected TCO expression (Figure S6B), it is possible that seed defects are only prevalent in tco- 1 due to the more upstream position of its T-DNA (Figure S6A). Finally, seed defects were not apparent in tco-1D or 2x35Sp::TCO-GFP plants, apart from an overall reduction in seed production due to their small stature (Figure 1E,I,J; Figure 2C,D). Thus, seed/embryo development may be more sensitive to reductions in TCO function compared to increased TCO levels. 


\subsection{TCO Interacts with and Is Phosphorylated by the Protein Kinase CK2}

Because transcriptional regulators often rely on protein-protein interactions for their activity, we sought to better understand TCO function by screening for physical interactors. To this end, we performed a yeast two-hybrid (Y2H) screen using TCO as bait and an Arabidopsis floral cDNA library as prey. Of the $1.7 \times 10^{6}$ yeast transformants isolated, 22 interactors were identified, all of which were clones of the catalytic subunit $(\alpha)$ of CK2. The CK2 holoenzyme is a tetramer of two $\alpha$ subunits and two regulatory $\beta$ subunits, with each type of subunit encoded by four different genes in Arabidopsis [36]. All CK2 subunits are broadly expressed throughout Arabidopsis development (including in roots, rosette leaves, reproductive stems, and flowers) but show some variability in subcellular localization patterns [36]. For instance, $\alpha$ subunits encoded by AtCKA1 (At5g67380), AtCKA2 (At3g50000) and AtCKA3 (At2g23080) localize to the nucleus (and are enriched in the nucleolus), whereas the protein product of AtCKA4 (At2g23070) localizes to the chloroplast [36]. The 22 identified TCO interactors consisted of 4 AtCKA1 and 18 AtCKA2 clones. Notably, the reported subcellular localization of these $\alpha$ subunits matches that of TCO, which is also localized to the nucleus (Figure 2F,G). The protein products of the isolated AtCKA1 and AtCKA2 cDNA clones interacted strongly with TCO when re-tested in directed $\mathrm{Y} 2 \mathrm{H}$ assays, even though each clone had a short truncation at the $5^{\prime}$ terminus of its coding sequence (Figure 6A). We also generated full-length AtCKA1 and AtCKA2 Y2H clones to test for interaction with TCO; however, the resulting proteins did not accumulate to an appreciable level (Figure 6B). Additionally, we tested the other nuclear-localized $\alpha$ subunit, AtCKA3, for interaction with TCO, and although this full-length subunit was efficiently expressed (Figure 6B), it failed to interact with TCO (Figure 6A). This indicates that TCO displays specificity regarding which CK2 subunits it interacts with.

Based on these $\mathrm{Y} 2 \mathrm{H}$ results, we hypothesized that TCO may be phosphorylated by CK2. A minimum consensus sequence for CK2-mediated phosphorylation has been defined as SXXE/D, with $\mathrm{S}$ serving as the phospho-acceptor site [37]. The $\mathrm{X}$ residue adjacent to the phospho-acceptor $\mathrm{S}$ is also commonly an acidic residue [37]. Based on these characteristics, we identified a putative consensus CK2 target site in the middle of the TCO protein ( $\mathrm{S}_{75} \mathrm{ESD}$ ) (Figure 6C). To assess whether posttranslational modification of this serine is important for TCO function, we generated phospho-deficient (S75A) and phospho-mimic (S75D) TCO variants, fused these to GFP, and placed them under the control of the $2 \times 35 \mathrm{~S}$ CaMV promoter. Transient expression in tobacco leaves showed that both 2x35Sp::mTCO(S75A)-GFP and 2x35Sp::mTCO(S75D)-GFP products localized to the nucleus and variably accumulated in subnuclear foci (Figure 7). This closely resembled the distribution of 2x35Sp::TCO-GFP (Figure 2F,G and Figure 7), indicating that the mutation of S75 did not affect the expression or subcellular localization of TCO protein. We also generated stable 2x35Sp::mTCO(S75A)-GFP and 2x35Sp::mTCO(S75D)-GFP Arabidopsis transgenic lines, but found that these resembled plants overexpressing wild-type TCO (Figure 8).

Because protein sites targeted by CK2 can vary from the defined consensus sequence [37], it is possible that CK2 phosphorylates residues of TCO other than S75. To experimentally identify such positions, we purified glutathione S-transferase (GST)-tagged TCO from a bacterial expression system, incubated this with recombinant CK2 enzyme, and performed mass spectrometry to assess TCO phosphorylation. This analysis identified a number of TCO serine residues phosphorylated by CK2 that were not modified in mock-treated control samples, including S11, S12, S73 and S74 (Figures 6C and 9). 
A

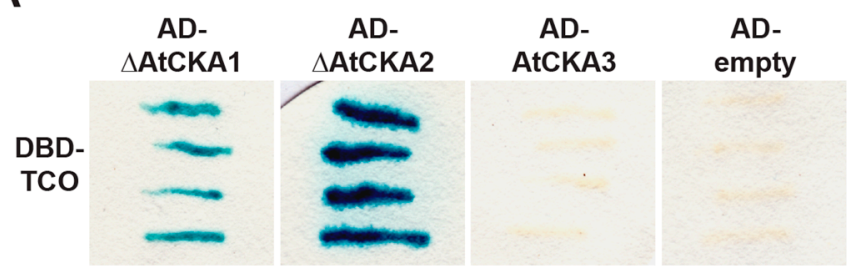

B
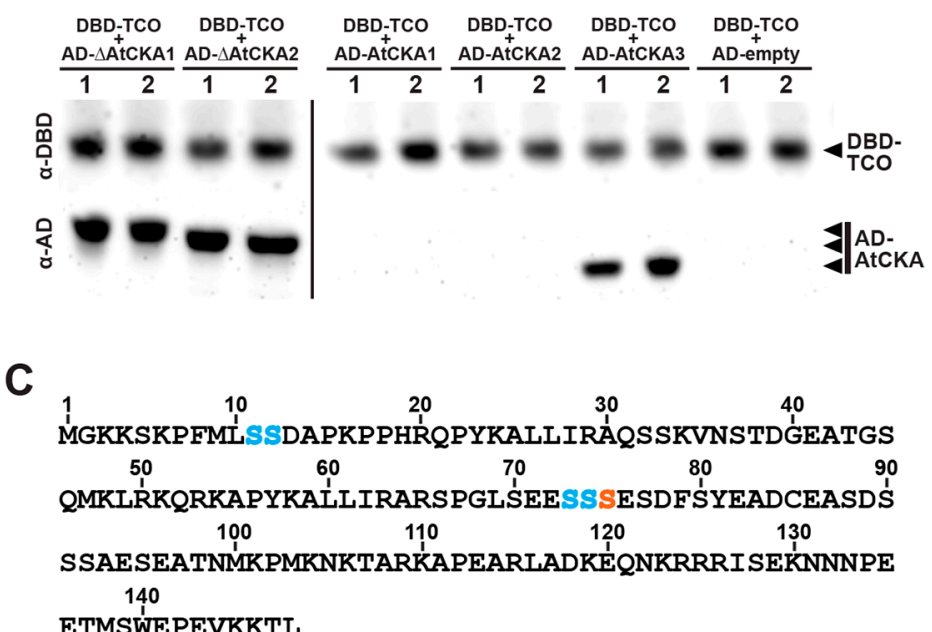

Figure 6. TCO protein interacts with catalytic subunits of the protein kinase CK2. (A) Yeast two-hybrid assays testing interaction between TCO (fused to the GAL4 DNA-binding domain (DBD)) and $\triangle$ AtCKA1(aa25-409), $\triangle$ AtCKA2(aa32-403) and AtCKA3(full-length) (each fused to the GAL4 activation domain (AD)), and an empty AD vector control are depicted. Positive interactions are indicated by blue coloration. (B) Western blot showing expression levels of yeast two-hybrid constructs. DBD-TCO, AD- $\triangle$ AtCKA1(aa25-409), AD- $\triangle$ AtCKA2(aa32-403) and AD-AtCKA3(full-length) show efficient expression in yeast. Full-length AD-AtCKA1 and AD-AtCKA2 protein does not accumulate to appreciable levels. The AD-empty vector control protein is not visible due to its small size. Two independent yeast transformants are shown for each vector combination. (C) Amino acid sequence of TCO. Serine (S) residues that reside within a putative consensus CK2 recognition sequence (SXXE/D) (orange) or that were experimentally determined to be modified by CK2 in this study (blue) are indicated.

To assess the biological relevance of these targeted serine residues, we designed various 2x35Sp::mTCO-GFP transgenes with phospho-deficient (S-to-A) or phospho-mimic (S-to-D) modifications. In all cases, these mTCO proteins accumulated to high levels and localized to the nucleus when transiently expressed in tobacco leaves (Figure 7), indicating that overall expression and subcellular distribution was not affected by the mutations. We also assessed whether stable transformation of these mTCO transgenes in Arabidopsis would result in phenotypes that differed from 2x35Sp::TCO-GFP. Stable Arabidopsis transformants were readily generated for the majority of the mTCO constructs, and these lines generally resembled 2x35Sp::TCO-GFP plants, as they lacked obvious seed patterning defects and displayed tightly curled leaves (Figure 8). Stable transgenic lines of 2x35Sp::mTCO(S11A,S12A,S73A,S74A)-GFP, however, could not be isolated despite repeated transformation attempts, and despite the fact that this mTCO transgene produced protein that accumulated to high levels when transiently expressed (Figure 7). This suggests that stable overexpression of this mTCO variant, which harbors multiple mutations that prevent CK2-mediated phosphorylation, compromises plant viability. At a mechanistic level, it remains to be determined how broadly preventing CK2-mediated phosphorylation of TCO negatively affects plant growth. 


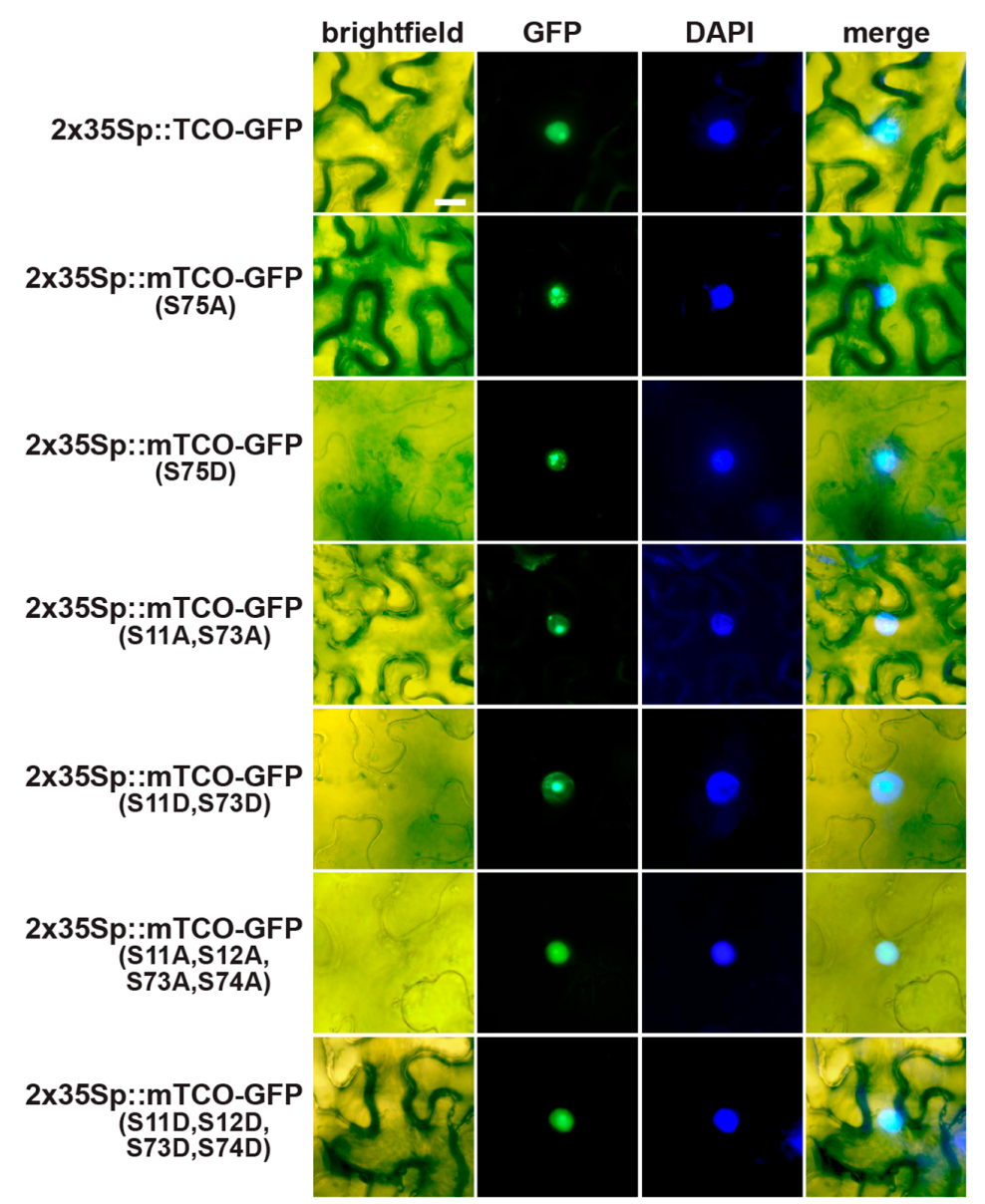

Figure 7. Phospho-deficient (S-to-A) and phospho-mimic (S-to-D) mutations of TCO do not alter protein subcellular localization. Overexpression constructs of wild-type TCO (2x35Sp::TCO-GFP) and mutated TCO variants (2x35Sp::mTCO-GFP) were transiently expressed in tobacco leaves. Proteins from all constructs accumulated to comparable levels (based on GFP fluorescence), localized to the nucleus, and variably displayed subnuclear speckles. Brightfield, GFP, and DAPI (nuclear stain) images are shown, along with a merged overlay of all three. Bars: $20 \mu \mathrm{m}$.
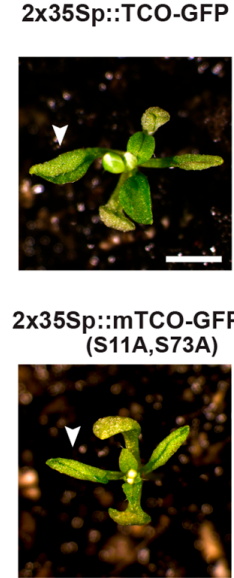

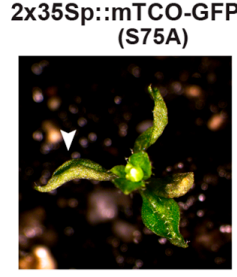

2x35Sp::mTCO-GFP (S11D,S73D)

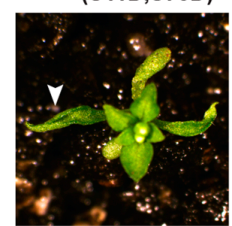

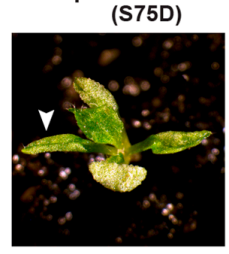

2x35Sp::mTCO-GFP (S11D,S12D,
S73D,S74D)

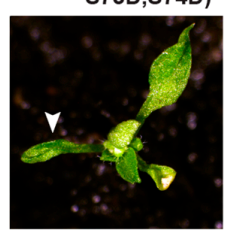

Figure 8. Phenotypic effects of overexpressing TCO-GFP transgenes in Arabidopsis. At 23 days after germination, primary transformants of phospho-deficient and phospho-mimic 2x35Sp::mTCO-GFP transgenes resembled those of 2x35Sp::TCO-GFP, all of which displayed short, curled leaves (arrowheads) and flowered early. The lone exception was 2x35Sp::mTCO(S11A,S12A,S73A,S74A)-GFP for which primary transformants could not be isolated. 

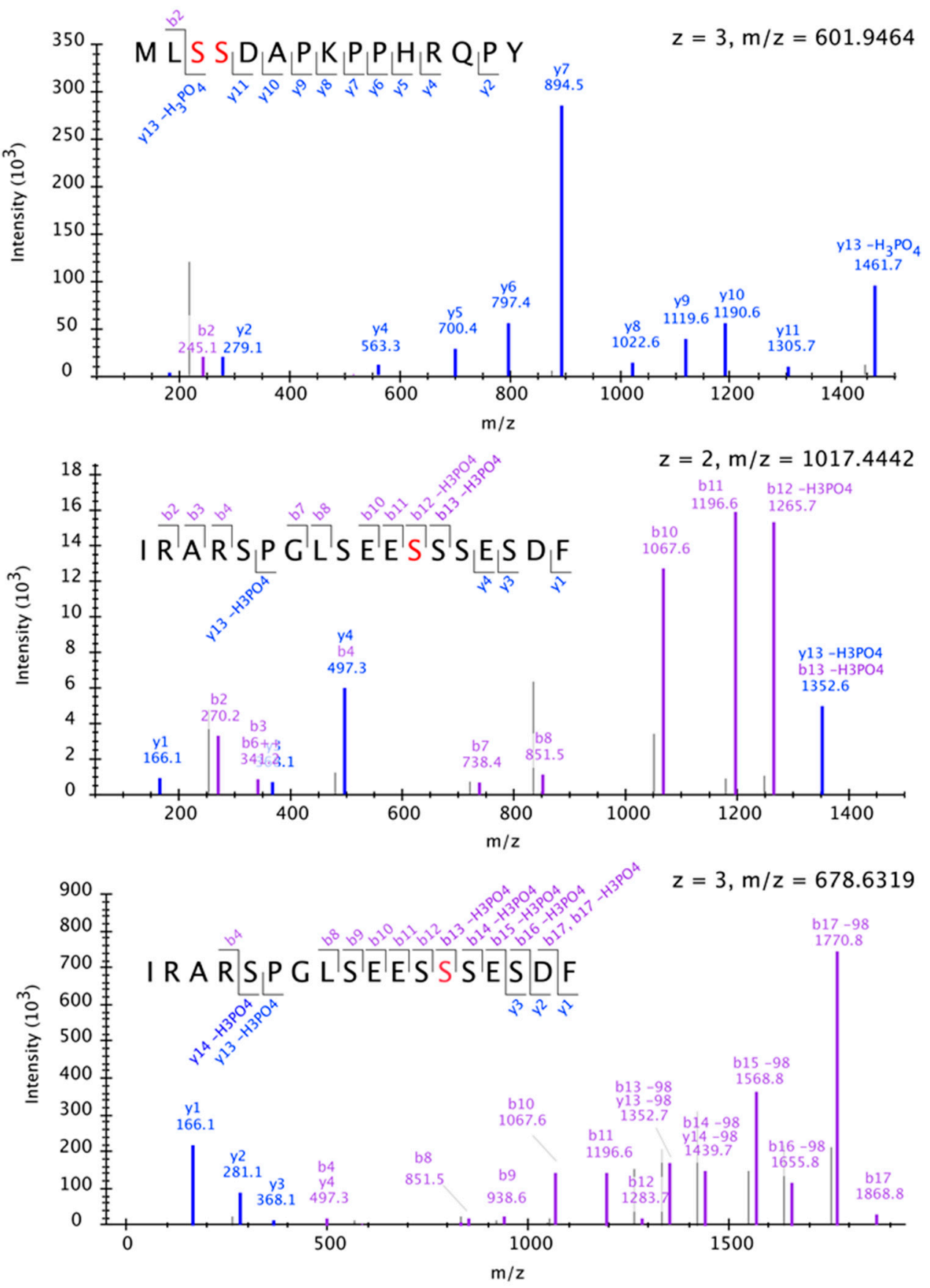

Figure 9. Mass spectrometry analysis of TCO residues phosphorylated by CK2. Representative annotated spectra for the phosphorylation sites identified are shown. Observed fragment ions are annotated in the displayed peptide sequences, with phosphorylation sites indicated by red-colored amino acids. Each peptide contains only a single phosphorylation site; however, in the case of the peptide MLSSDAPKPPHRQPY (top), the exact site of phosphorylation is ambiguous between two adjacent serine residues.

\section{Discussion}

The development of multicellular organisms relies on complex gene expression patterns established through transcriptional activation and repression. We have identified TCO, a putative transcriptional regulator in Arabidopsis, whose overexpression causes broad misregulation of reproductive genes in the vegetative stage, resulting in patterning abnormalities. This collection of defects, which includes curled leaves and early flowering, resembles mutants of chromatin-modifying 
factors $[2,31,38]$, implicating a role for TCO in this mode of transcriptional regulation. This is further supported by the nuclear localization of TCO, which tends to accumulate in distinct foci or "speckles" reminiscent of known chromatin regulators [4,30-33]. Moreover, the enhancement and suppression of tco-1D developmental defects by clf and ult1, respectively, suggests that TCO may regulate a shared set of target genes with these well-characterized chromatin modifiers. While these genetic interactions were apparent in plants ectopically expressing TCO (Figure 4A-K; Figure S5A-D), functional overlap may also occur in their normal domains of expression. Specifically, reporter gene analyses demonstrated that TCO acts during embryo/seed development, and both CLF and ULT1 are expressed in developing seeds [34,39]. TCO may also interact with other chromatin modifiers to influence gene expression in these tissues. Indeed, a recent unpublished report describes a physical interaction between TCO (therein named EFC) and Multicopy Suppressor of Ira1 (MSI1) [40], a core component of Arabidopsis PRC2 complexes [5]. While these observations support a role for TCO in chromatin-dependent transcriptional regulation, the mechanism by which TCO participates in these processes is unclear, given its small size and lack of conserved functional domains.

Our determination that the protein kinase CK2 interacts with and phosphorylates TCO provides some insight into the nature of its activity. Phosphorylation of TCO could potentially affect its function in a variety of ways, including by altering its subcellular localization, its interaction with other proteins, and/or its association with chromatin [9]. Mutation of TCO serine residues targeted by CK2, however, did not alter its nuclear localization or speckle formation, suggesting that CK2-mediated phosphorylation influences other aspects of TCO activity. Similarly, overexpression of most TCO variants with either phospho-deficient or phospho-mimic mutations did not produce phenotypes that differed from plants overexpressing wild-type TCO. Here, functional differences between these various transgenes may have been obscured by their high expression levels. Support for this notion comes from analyses of the Arabidopsis bZIP transcription factor TGA2, which is also targeted by CK2. While mutation of TGA2 phosphorylated residues did not affect its nuclear localization, it compromised its ability to bind DNA [41]. Even so, overexpression of wild-type and mutated TGA2 activated target genes to the same extent in planta, leading to the suggestion that high protein levels masked functional disparity between the TGA2 variants [41]. That CK2-mediated phosphorylation of TCO is biologically relevant is suggested by our inability to isolate Arabidopsis transgenic lines overexpressing mTCO with all four targeted serine residues mutated to alanine (S11A,S12A,S73A,S74A), despite efficient transient expression of this same construct in tobacco cells. Although the reason for this is unclear, it is possible that phosphorylation of TCO modulates its transcriptional activity, and that overexpressing phospho-deficient TCO broadly disrupts gene expression to an extent that compromises plant viability.

TCO may interact with CK2 not only to mediate its own phosphorylation, but to recruit CK2 to protein complexes to target other factors. The use of protein-protein interaction as a means to modulate kinase activity has been previously proposed for CK2 [42,43], and the reported interaction between TCO and the PRC2 component MSI1 [40] could facilitate this type of mechanism. CK2-mediated phosphorylation of PRC factors has been reported to influence their protein-protein interactions, histone-binding properties and enzymatic activities [12-14,44], raising the possibility that mutation of TCO indirectly affects the ability of CK2 to target chromatin regulators. If the Enhancer of Zeste $(\mathrm{E}(\mathrm{z}))$ protein CLF is one such chromatin regulator, this could explain why tco-1D phenocopies $c l f$. In a similar manner, phosphorylation of the human homolog of E(z), EZH2, interferes with its ability to bind and methylate histones, resulting in derepression of target genes [10].

Contrasting the broad gene misregulation in $t c o-1 D$ seedlings, tco loss-of-function alleles affected gene expression to a lesser extent when tested in young silique tissue (Figure 5C,D). While this can be explained by the restricted domain of expression naturally displayed by TCO, the reason that both gain- and loss-of-function alleles displayed gene upregulation is unclear. Removing TCO function from its natural domains of expression could disrupt protein complexes that rely on TCO and/or CK2 activity, resulting in gene derepression. Strong, ectopic expression of TCO could similarly affect gene expression if this causes TCO to interfere with the formation of protein complex(es). Indeed, 
overexpression of factors that operate in protein complexes can mimic loss-of-function defects due to antimorphic effects [45]. Based on the reported binding of TCO to MSI1 [40], it is possible that high levels of TCO interfere with the ability of MSI1 to associate with other binding partners, including LIKE HETEROCHROMATIN PROTEIN 1/TERMINAL FLOWER 2 (LHP1/TFL2), which performs a Pc-like role in Arabidopsis [46,47]. Consistent with this scenario, tco-1D plants phenotypically resemble $\operatorname{lhp} 1 /$ tfl2 loss-of-function mutants $[31,48]$ and misexpress genes that rely on LHP1/TFL2-mediated repression such as $A G$ and SEP3 [49].

Notably, the most striking developmental defects caused by TCO overexpression arose in tissues that do not naturally express TCO, such as vegetative leaves. Growth responses that normally operate in the absence of TCO may, therefore, be particularly sensitive to artificial exposure to TCO activity. In these cases, TCO may engage in non-specific protein interactions, interfere with the composition of transcriptional regulatory complexes, and/or broadly impinge on chromatin topology, as suggested by widespread gene misregulation in tco-1D seedlings (Figure 3F; Figure S4A-D). In contrast, TCO overexpression did not appear to affect tissues that normally express TCO, namely the seed (Figure 5A,B). Specifically, tco-1D and 2x35Sp::TCO-GFP transgenic backgrounds lacked obvious seed abnormalities, even though such defects were present in the loss-of-function allele tco-1 (Figure $\mathrm{S7C}, \mathrm{D}, \mathrm{H}, \mathrm{L}$ ). These observations indicate that growth processes that already involve TCO activity, such as seed development, may be able to accommodate further increases in TCO levels. Conversely, these same processes are likely to become compromised if TCO activity is reduced or abolished, as displayed by tco-1 mutant seeds.

A future challenge will be to better clarify the specific endogenous role of TCO in Arabidopsis development. Notably, TCO has been identified as a candidate imprinted gene that displays seed-specific expression and hypomethylation in the endosperm [50]. Many imprinted genes play roles in endosperm/seed development [51], including a number of chromatin regulators [52]. It is plausible that TCO also contributes to this mode of transcriptional regulation during seed development, as our experimental data implicates TCO in the regulation of chromatin. TCO-like genes are also present in the genomes of other Brassicaceae species (Figure S2A-D), and their functional characterization will provide further insight into the role of TCO and the extent to which this role is conserved in other plant species.

\section{Materials and Methods}

\subsection{Plant Material}

Plants were grown on soil in a growth chamber under a 16-hour light/8-hour dark cycle. The Landsberg erecta (Ler) ecotype of Arabidopsis thaliana (L.) Heynh served as wild type, unless otherwise noted. Genetic analyses used the previously described mutants ag-1 [53], clf-2 [2], ult1-1 and ult1-2 [54]. PCR-based genotyping of $c l f-2, u l t 1-1$ and ult1-2 alleles followed established protocols $[4,55]$. The tco-1D gain-of-function mutant was isolated from an activation-tagging screen of Ler using T-DNA vector pSKI015 [56]. The tco-1 and tco-2 loss-of-function mutants are T-DNA insertion alleles (SALK_018803 and SALK_112041, respectively) [57]. Analyses involving these insertion mutants used the Columbia-0 (Col-0) ecotype of Arabidopsis as wild type.

\subsection{Reverse Transcription-Polymerase Chain Reaction (RT-PCR)}

An Invitrogen SuperScript first-strand synthesis system (Thermo Fisher Scientific, Waltham, MA, USA) was used for reverse transcription of total RNA samples purified using an RNeasy Plant Mini Kit (Qiagen Inc., Germantown, MD, USA). Quantitative real-time RT-PCR on cDNA samples was performed with a Mx3005P QPCR system (Agilent Technologies, Santa Clara, CA, USA) using PerfeCTa SYBR Green SuperMix (Quanta Biosciences Inc., Beverly, MA, USA). Data analysis was carried out with MxPro QPCR software (Agilent Technologies). Relative expression levels were normalized against ACTIN7 [58]. Primer sequences used for cDNA amplification are provided in Table S1. 


\subsection{Transgenic Plant Lines}

The genomic location of the activation-tagging T-DNA in tco-1D was determined using TAIL PCR [15]. To generate 2x35Sp::TCO-GFP, the TCO gene was amplified by PCR and cloned into pCR-Blunt II-TOPO (Thermo Fisher Scientific). The TCO gene was then digested from this vector and introduced into the PstI-HindIII sites of plasmid pBJ36 [59], placing TCO under the control of the 2x35S CaMV promoter and in-frame with the green fluorescent protein (GFP). This fusion gene was subcloned into the NotI site of binary vector pART27 [60] and transformed into the Ler ecotype using the Agrobacterium-mediated floral dip method [61]. All 2x35Sp::TCO-GFP mutant variants were generated using the above strategy, modified as follows: $\mathrm{mTCO}(\mathrm{S} 75 \mathrm{~A})$ and $\mathrm{mTCO}(\mathrm{S} 75 \mathrm{D})$ were produced by PCR-based site-directed mutagenesis, and mTCO(S11A,S73A), mTCO(S11D,S73D), mTCO(S11A,S12A,S73A,S74A) and mTCO(S11D,S12D,S73D,S74D) were ordered as custom-designed gene fragments (Integrated DNA Technologies, Inc., Skokie, IL, USA). 2x35Sp::YFP and all GFP reporter constructs were transiently expressed in tobacco leaves as previously described [62]. TCOp::TCO-GUS is a translational fusion between TCO and $\beta$-glucuronidase (GUS), flanked by the promoter $(2.6 \mathrm{~kb}$ upstream of start codon) and $3^{\prime}$ non-coding regulatory sequence (1.5 $\mathrm{kb}$ downstream of stop codon) of the TCO gene. This fusion gene was assembled in pBJ36 and subcloned into pMLBART [59] for transformation into the Arabidopsis Ler ecotype. All primer sequences used in PCR are provided in Table S1.

\subsection{Histology and Microscopy}

Siliques of Arabidopsis plants expressing TCOp::TCO-GUS were GUS-stained for $24 \mathrm{~h}$ as previously detailed [58], fixed overnight in FAA (3.7\% formaldehyde, 50\% ethanol, 5\% glacial acetic acid), embedded in paraffin, and sectioned to a thickness of $20 \mu \mathrm{m}$. Sections were then deparaffinized, rehydrated through a reverse ethanol series (100\% to $30 \%)$, incubated in water, mounted and imaged. For embryo dissection, seeds were fixed in $4 \%$ paraformaldehyde under vacuum for $2 \mathrm{~h}$, rinsed three times in phosphate buffered saline, and incubated in clearing solution (6M urea, $30 \%$ glycerol, $0.1 \%$ Triton X-100) [63] for 3 weeks at $4{ }^{\circ} \mathrm{C}$. Embryos were liberated from the seed coat by applying gentle pressure. An Olympus SZX16 dissecting microscope was used to capture images of live plant tissues, while an Olympus BX61 compound microscope was used to capture images of fixed/sectioned tissues and GFP fluorescence (Olympus, Center Valley, PA, USA).

\subsection{TCO Protein Expression and Analyses}

Yeast two-hybrid screens using TCO as bait and an Arabidopsis floral cDNA library as prey were performed as previously described [62]. Directed yeast two-hybrid assays and Western blotting were conducted as previously reported [64]. GST protein fusions were expressed and purified as described [64]. Prior to incubation with recombinant CK2 enzyme (New England Biolabs, Inc., Ipswich, MA, USA), GST-TCO protein bound to glutathione agarose beads was washed twice with PBSI buffer (10 $\mathrm{mM} \mathrm{Na}_{2} \mathrm{HPO}_{4}, 2 \mathrm{mM} \mathrm{KH} \mathrm{PO}_{4}, 2.7 \mathrm{mM} \mathrm{KCl}, 137 \mathrm{mM} \mathrm{NaCl}, 0.1 \%$ IGEPAL CA-620) and twice with accompanying Protein Kinase (PK) reaction buffer. $45 \mu \mathrm{L}$ of PK buffer was added to the beads, followed by $1 \mu \mathrm{L}$ of $10 \mathrm{mM}$ ATP and $1000 \mathrm{U}$ of CK2 enzyme. A mock GST-TCO reaction in the absence of CK2 enzyme was performed in parallel. The on-bead reactions were incubated at $30^{\circ} \mathrm{C}$ for $1 \mathrm{~h}$ and subsequently washed twice in PBSI. GST-TCO protein was eluted with $20 \mathrm{mM}$ reduced glutathione (50 mM Tris- $\mathrm{HCl}, \mathrm{pH} 8)$, followed by a second elution in low salt buffer $(150 \mathrm{mM} \mathrm{NaCl}, 50 \mathrm{mM}$ Tris-HCl, pH 7.5, 1 mM EDTA) containing 0.05\% RapiGest SF surfactant (Waters Corporation, Milford, MA, USA).

\subsection{Mass Spectrometry Sample Preparation, Acquisition and Data Analysis}

Eluted GST-TCO samples were prepared by diluting in $50 \mathrm{mM}$ ammonium bicarbonate (pH 8 ) and digested with $1 \mu \mathrm{g} / \mu \mathrm{L}$ chymotrypsin at $37^{\circ} \mathrm{C}$ overnight. Samples were then acidified by the addition 
of $10 \%$ trifluoroacetic acid to $\mathrm{pH} 2$ and desalted in $\mathrm{C} 18$ stage tips. The peptides were resuspended in $4 \%$ formic acid and 3\% acetonitrile, and approximately $2 \mu \mathrm{L}$ of the $15 \mu \mathrm{L}$ sample were loaded onto a $75 \mu \mathrm{m}$ ID column packed with $25 \mathrm{~cm}$ of Reprosil C18 $1.9 \mu \mathrm{m}, 120 \AA$ A particles (Dr. Maisch High-Performance Liquid Chromatograph (HPLC) GmbH, Ammerbuch, Germany). Peptides were eluted into an Orbitrap Q-Exactive Plus mass spectrometer (Thermo Fisher) by gradient elution delivered by an Easy1200 nLC system (Thermo Fisher), using a gradient from $5 \%$ to $29 \%$ acetonitrile over $53 \mathrm{~min}$. All mass spectrometry (MS) spectra were collected with orbitrap detection (70 K resolution). All data were searched simultaneously against the wild-type and mutant TCO protein sequences, as well as the yeast protein database (downloaded 13 January 2015) using MaxQuant [65]. Peptide, protein and phosphorylation sites identification was filtered to a $1 \%$ false-discovery rate. Spectra were annotated using Skyline [66]. The mass spectrometry data files (raw and search results) have been deposited to the ProteomeXchange Consortium (http:/ / proteomecentral.proteomexchange.org) via the PRIDE partner repository [67] with the dataset identifier PXD011565.

Supplementary Materials: Supplementary materials can be found at http:/ / www.mdpi.com/1422-0067/20/ 1/99/s1. Figure S1: Expression levels of genes flanking the activation-tagging T-DNA in tco-1D. Figure S2: Arabidopsis TCO/At4g23110 shares sequence similarity to proteins found in other Brassicaceae species. Figure S3: Localization of TCO-GFP in stable transgenic Arabidopsis lines. Figure S4: Expression levels of floral genes in wild-type and tco-1D vegetative tissues. Figure S5: Developmental defects of $t c o-1 D$ leaves are suppressed by the semi-dominant mutant ult1-1. Figure S6: TCO expression in the Arabidopsis T-DNA insertion alleles tco-1 and tco-2. Figure S7: Seed defects of Arabidopsis insertion mutant tco-1. Table S1: List of primers used in this study.

Author Contributions: Conceptualization, B.Y.C., N.J.K. and N.T.K.; Investigation, L.M.W., K.L.D.R, N.S.C., E.J.S., D.L.S., B.Y.C. and N.T.K.; Writing-Original Draft Preparation, N.T.K.; Writing-Reviewing and Editing, B.Y.C. and N.T.K.; Supervision, N.J.K. and N.T.K.; Funding Acquisition, N.T.K.

Funding: This research was funded by the National Institute of General Medical Sciences of the National Institutes of Health under award number R15GM114733 to N.T.K. The content is solely the responsibility of the authors and does not necessarily represent the official views of the National Institutes of Health.

Acknowledgments: We thank J. Long for valuable advice and support.

Conflicts of Interest: The authors declare no conflict of interest. The funders had no role in the design of the study; in the collection, analyses, or interpretation of data; in the writing of the manuscript, or in the decision to publish the results.

\section{Abbreviations}

DAG days after germination

DAP days after pollination

Y2H yeast two-hybrid

\section{References}

1. Schuettengruber, B.; Bourbon, H.M.; Di Croce, L.; Cavalli, G. Genome regulation by Polycomb and Trithorax: 70 years and counting. Cell 2017, 171,34-57. [CrossRef] [PubMed]

2. Goodrich, J.; Puangsomlee, P.; Martin, M.; Long, D.; Meyerowitz, E.M.; Coupland, G. A Polycomb-group gene regulates homeotic gene expression in Arabidopsis. Nature 1997, 386, 44-51. [CrossRef] [PubMed]

3. Saleh, A.; Al-Abdallat, A.; Ndamukong, I.; Alvarez-Venegas, R.; Avramova, Z. The Arabidopsis homologs of trithorax (ATX1) and enhancer of zeste (CLF) establish 'bivalent chromatin marks' at the silent AGAMOUS locus. Nucleic Acids Res. 2007, 35, 6290-6296. [CrossRef] [PubMed]

4. Carles, C.C.; Fletcher, J.C. The SAND domain protein ULTRAPETALA1 acts as a trithorax group factor to regulate cell fate in plants. Genes Dev. 2009, 23, 2723-2728. [CrossRef] [PubMed]

5. Bemer, M.; Grossniklaus, U. Dynamic regulation of Polycomb group activity during plant development. Curr. Opin. Plant Biol. 2012, 15, 523-529. [CrossRef] [PubMed]

6. De la Paz Sanchez, M.; Aceves-Garcia, P.; Petrone, E.; Steckenborn, S.; Vega-Leon, R.; Alvarez-Buylla, E.R.; Garay-Arroyo, A.; Garcia-Ponce, B. The impact of Polycomb group (PcG) and Trithorax group (TrxG) epigenetic factors in plant plasticity. New Phytol. 2015, 208, 684-694. [CrossRef] [PubMed] 
7. Perino, M.; Veenstra, G.J.C. Chromatin control of developmental dynamics and plasticity. Dev. Cell 2016, 38, 610-620. [CrossRef]

8. Niessen, H.E.C.; Demmers, J.A.; Voncken, J.W. Talking to chromatin: Post-translational modulation of polycomb group function. Epigenet. Chromatin 2009, 2, 10. [CrossRef]

9. Bigeard, J.; Rayapuram, N.; Pflieger, D.; Hirt, H. Phosphorylation-dependent regulation of plant chromatin and chromatin-associated proteins. Proteomics 2014, 14, 2127-2140. [CrossRef]

10. Cha, T.L.; Zhou, B.P.; Xia, W.; Wu, Y.; Yang, C.C.; Chen, C.T.; Ping, B.; Otte, A.P.; Hung, M.C. Akt-mediated phosphorylation of EZH2 suppresses methylation of lysine 27 in histone H3. Science 2005, 310, 306-310. [CrossRef]

11. Muchardt, C.; Reyes, J.C.; Bourachot, B.; Legouy, E.; Yaniv, M. The hbrm and BRG-1 proteins, components of the human SNF/SWI complex, are phosphorylated and excluded from the condensed chromosomes during mitosis. EMBO J. 1996, 15, 3394-3402. [CrossRef]

12. Ng, J.; Hart, C.M.; Morgan, K.; Simon, J.A. A Drosophila ESC-E(Z) protein complex is distinct from other Polycomb group complexes and contains covalently modified ESC. Mol. Cell. Biol. 2000, 20, 3069-3078. [CrossRef] [PubMed]

13. Tie, F.; Siebold, A.P.; Harte, P.J. The N-terminus of Drosophila ESC mediates its phosphorylation and dimerization. Biochem. Biophys. Res. Commun. 2005, 332, 622-632. [CrossRef] [PubMed]

14. Hatano, A.; Matsumoto, M.; Higashinakagawa, T.; Nakayama, K.I. Phosphorylation of the chromodomain changes the binding specificity of $\mathrm{Cbx} 2$ for methylated histone H3. Biochem. Biophys. Res. Commun. 2010, 397, 93-99. [CrossRef]

15. Liu, Y.G.; Mitsukawa, N.; Oosumi, T.; Whittier, R.F. Efficient isolation and mapping of Arabidopsis thaliana T-DNA insert junctions by thermal asymmetric interlaced PCR. Plant J. 1995, 8, 457-463. [CrossRef]

16. Berardini, T.Z.; Reiser, L.; Li, D.; Mezheritsky, Y.; Muller, R.; Strait, E.; Huala, E. The Arabidopsis Information Resource: Making and mining the "gold standard" annotated reference plant genome. Genesis 2015, 53, 474-485. [CrossRef] [PubMed]

17. Altschul, S.F.; Gish, W.; Miller, W.; Myers, E.W.; Lipman, D.J. Basic local alignment search tool. J. Mol. Biol. 1990, 215, 403-410. [CrossRef]

18. Bowman, J.L.; Smyth, D.R.; Meyerowitz, E.M. Genetic interactions among floral homeotic genes of Arabidopsis. Development 1991, 112, 1-20. [PubMed]

19. Coen, E.S.; Meyerowitz, E.M. The war of the whorls: Genetic interactions controlling flower development. Nature 1991, 353, 31-37. [CrossRef] [PubMed]

20. Kardailsky, I.; Shukla, V.K.; Ahn, J.H.; Dagenais, N.; Christensen, S.K.; Nguyen, J.T.; Chory, J.; Harrison, M.J.; Weigel, D. Activation tagging of the floral inducer FT. Science 1999, 286, 1962-1965. [CrossRef]

21. Kobayashi, Y.; Kaya, H.; Goto, K.; Iwabuchi, M.; Araki, T. A pair of related genes with antagonistic roles in mediating flowering signals. Science 1999, 286, 1960-1962. [CrossRef] [PubMed]

22. Mizukami, Y.; Ma, H. Ectopic expression of the floral homeotic gene AGAMOUS in transgenic Arabidopsis plants alters floral organ identity. Cell 1992, 71, 119-131. [CrossRef]

23. Mandel, M.A.; Yanofsky, M.F. A gene triggering flower formation in Arabidopsis. Nature 1995, 377, 522-524. [CrossRef] [PubMed]

24. Weigel, D.; Nilsson, O. A developmental switch sufficient for flower initiation in diverse plants. Nature 1995, 377, 495-500. [CrossRef] [PubMed]

25. Krizek, B.A.; Meyerowitz, E.M. The Arabidopsis homeotic genes APETALA3 and PISTILLATA are sufficient to provide the B class organ identity function. Development 1996, 122, 11-22. [PubMed]

26. Pelaz, S.; Gustafson-Brown, C.; Kohalmi, S.E.; Crosby, W.L.; Yanofsky, M.F. APETALA1 and SEPALLATA3 interact to promote flower development. Plant J. 2001, 26, 385-394. [CrossRef] [PubMed]

27. Nesi, N.; Debeaujon, I.; Jond, C.; Stewart, A.J.; Jenkins, G.I.; Caboche, M.; Lepiniec, L. The TRANSPARENT TESTA16 locus encodes the ARABIDOPSIS BSISTER MADS domain protein and is required for proper development and pigmentation of the seed coat. Plant Cell 2002, 14, 2463-2479. [CrossRef] [PubMed]

28. Favaro, R.; Pinyopich, A.; Battaglia, R.; Kooiker, M.; Borghi, L.; Ditta, G.; Yanofsky, M.F.; Kater, M.M.; Colombo, L. MADS-box protein complexes control carpel and ovule development in Arabidopsis. Plant Cell 2003, 15, 2603-2611. [CrossRef]

29. Pinyopich, A.; Ditta, G.S.; Savidge, B.; Liljegren, S.J.; Baumann, E.; Wisman, E.; Yanofsky, M.F. Assessing the redundancy of MADS-box genes during carpel and ovule development. Nature 2003, 424, 85-88. [CrossRef] 
30. Dietzel, S.; Niemann, H.; Bruckner, B.; Maurange, C.; Paro, R. The nuclear distribution of Polycomb during Drosophila melanogaster development shown with a GFP fusion protein. Chromosoma 1999, 108, 83-94. [CrossRef]

31. Gaudin, V.; Libault, M.; Pouteau, S.; Juul, T.; Zhao, G.; Lefebvre, D.; Grandjean, O. Mutations in LIKE HETEROCHROMATIN PROTEIN 1 affect flowering time and plant architecture in Arabidopsis. Development 2001, 128, 4847-4858. [PubMed]

32. Calonje, M.; Sanchez, R.; Chen, L.; Sung, Z.R. EMBRYONIC FLOWER1 participates in Polycomb group-mediated AG gene silencing in Arabidopsis. Plant Cell 2008, 20, 277-291. [CrossRef] [PubMed]

33. Hernandez-Munoz, I.; Lund, A.H.; van der Stoop, P.; Boutsma, E.; Muijrers, I.; Verhoeven, E.; Nusinow, D.A.; Panning, B.; Marahrens, Y.; van Lohuizen, M. Stable X chromosome inactivation involves the PRC1 Polycomb complex and requires histone MACROH2A1 and the CULLIN3/SPOP ubiquitin E3 ligase. Proc. Natl. Acad. Sci. USA 2005, 102, 7635-7640. [CrossRef] [PubMed]

34. Carles, C.C.; Choffnes-Inada, D.; Reville, K.; Lertpiriyapong, K.; Fletcher, J.C. ULTRAPETALA1 encodes a SAND domain putative transcriptional regulator that controls shoot and floral meristem activity in Arabidopsis. Development 2005, 132, 897-911. [CrossRef] [PubMed]

35. Klepikova, A.V.; Kasianov, A.S.; Gerasimov, E.S.; Logacheva, M.D.; Penin, A.A. A high resolution map of the Arabidopsis thaliana developmental transcriptome based on RNA-seq profiling. Plant J. 2016, 88, 1058-1070. [CrossRef] [PubMed]

36. Salinas, P.; Fuentes, D.; Vidal, E.; Jordana, X.; Echeverria, M.; Holuigue, L. An extensive survey of CK2 $\alpha$ and $\beta$ subunits in Arabidopsis: Multiple isoforms exhibit differential subcellular localization. Plant Cell Physiol. 2006, 47, 1295-1308. [CrossRef] [PubMed]

37. Meggio, F.; Pinna, L.A. One-thousand-and-one substrates of protein kinase CK2? FASEB J. 2003, 17, 349-368. [CrossRef] [PubMed]

38. Chanvivattana, Y.; Bishopp, A.; Schubert, D.; Stock, C.; Moon, Y.H.; Sung, Z.R.; Goodrich, J. Interaction of Polycomb-group proteins controlling flowering in Arabidopsis. Development 2004, 131, 5263-5276. [CrossRef]

39. Spillane, C.; Schmid, K.J.; Laoueille-Duprat, S.; Pien, S.; Escobar-Restrepo, J.M.; Baroux, C.; Gagliardini, V.; Page, D.R.; Wolfe, K.H.; Grossniklaus, U. Positive darwinian selection at the imprinted MEDEA locus in plants. Nature 2007, 448, 349-352. [CrossRef]

40. Delgerekh, N. Study on the Role of EARLY FLOWERING AND CURLY LEAVES (EFC) in the FIS2-PRC2 Complex of Arabidopsis thaliana. Master's Thesis, Seoul National University, Seoul, Korea, 2016.

41. Kang, H.G.; Klessig, D.F. Salicylic acid-inducible Arabidopsis CK2-like activity phosphorylates TGA2. Plant Mol. Biol. 2005, 57, 541-557. [CrossRef]

42. Allende-Vega, N.; McKenzie, L.; Meek, D. Transcription factor TAFII250 phosphorylates the acidic domain of Mdm2 through recruitment of protein kinase CK2. Mol. Cell. Biochem. 2008, 316, 99-106. [CrossRef] [PubMed]

43. Litchfield, D.W. Protein kinase CK2: Structure, regulation and role in cellular decisions of life and death. Biochem. J. 2003, 369, 1-15. [CrossRef] [PubMed]

44. Gao, Z.; Lee, P.; Stafford, J.M.; von Schimmelmann, M.; Schaefer, A.; Reinberg, D. An AUTS2-Polycomb complex activates gene expression in the CNS. Nature 2014, 516, 349-354. [CrossRef] [PubMed]

45. Prelich, G. Gene overexpression: Uses, mechanisms, and interpretation. Genetics 2012, 190, 841-854. [CrossRef] [PubMed]

46. Turck, F.; Roudier, F.; Farrona, S.; Martin-Magniette, M.L.; Guillaume, E.; Buisine, N.; Gagnot, S.; Martienssen, R.A.; Coupland, G.; Colot, V. Arabidopsis TFL2/LHP1 specifically associates with genes marked by trimethylation of histone H3 lysine 27. PLoS Genet. 2007, 3, e86. [CrossRef] [PubMed]

47. Zhang, X.; Germann, S.; Blus, B.J.; Khorasanizadeh, S.; Gaudin, V.; Jacobsen, S.E. The Arabidopsis LHP1 protein colocalizes with histone H3 Lys27 trimethylation. Nat. Struct. Mol. Biol. 2007, 14, 869-871. [CrossRef] [PubMed]

48. Larsson, A.S.; Landberg, K.; Meeks-Wagner, D.R. The TERMINAL FLOWER2 (TFL2) gene controls the reproductive transition and meristem identity in Arabidopsis thaliana. Genetics 1998, 149, 597-605. [PubMed]

49. Derkacheva, M.; Steinbach, Y.; Wildhaber, T.; Mozgova, I.; Mahrez, W.; Nanni, P.; Bischof, S.; Gruissem, W.; Hennig, L. Arabidopsis MSI1 connects LHP1 to PRC2 complexes. EMBO J. 2013, 32, 2073-2085. [CrossRef] [PubMed]

50. Gehring, M.; Bubb, K.L.; Henikoff, S. Extensive demethylation of repetitive elements during seed development underlies gene imprinting. Science 2009, 324, 1447-1451. [CrossRef] 
51. Gehring, M.; Satyaki, P.R. Endosperm and imprinting, inextricably linked. Plant Physiol. 2017, 173, $143-154$. [CrossRef]

52. Xiao, J.; Wagner, D. Polycomb repression in the regulation of growth and development in Arabidopsis. Curr. Opin. Plant Biol. 2015, 23, 15-24. [CrossRef] [PubMed]

53. Bowman, J.L.; Smyth, D.R.; Meyerowitz, E.M. Genes directing flower development in Arabidopsis. Plant Cell 1989, 1, 37-52. [CrossRef] [PubMed]

54. Fletcher, J.C. The ULTRAPETALA gene controls shoot and floral meristem size in Arabidopsis. Development 2001, 128, 1323-1333. [PubMed]

55. Hacisalihoglu, G.; Hilgert, U.; Nash, E.B.; Micklos, D.A. An innovative plant genomics and gene annotation program for high school, community college, and university faculty. CBE Life Sci. Educ. 2008, 7, 310-316. [CrossRef] [PubMed]

56. Weigel, D.; Ahn, J.H.; Blazquez, M.A.; Borevitz, J.O.; Christensen, S.K.; Frankhauser, C.; Ferrandiz, C.; Kardailsky, I.; Malancharuvil, E.J.; Neff, M.M.; et al. Activation tagging in Arabidopsis. Plant Physiol. 2000, 122, 1003-1013. [CrossRef] [PubMed]

57. Alonso, J.M.; Stepanova, A.N.; Leisse, T.J.; Kim, C.J.; Chen, H.; Shinn, P.; Stevenson, D.K.; Zimmerman, J.; Barajas, P.; Cheuk, R.; et al. Genome-wide insertional mutagenesis of Arabidopsis thaliana. Science 2003, 301, 653-657. [CrossRef] [PubMed]

58. Krogan, N.T.; Yin, X.; Ckurshumova, W.; Berleth, T. Distinct subclades of Aux/IAA genes are direct targets of ARF5/MP transcriptional regulation. New Phytol. 2014, 204, 474-483. [CrossRef]

59. Eshed, Y.; Baum, S.F.; Perea, J.V.; Bowman, J.L. Establishment of polarity in lateral organs of plants. Curr. Biol. 2001, 11, 1251-1260. [CrossRef]

60. Gleave, A.P. A versatile binary vector system with a T-DNA organisational structure conducive to efficient integration of cloned DNA into the plant genome. Plant Mol. Biol. 1992, 20, 1203-1207. [CrossRef]

61. Clough, S.J.; Bent, A.F. Floral dip: A simplified method for Agrobacterium-mediated transformation of Arabidopsis thaliana. Plant J. 1998, 16, 735-743. [CrossRef]

62. Szemenyei, H.; Hannon, M.; Long, J.A. TOPLESS mediates auxin-dependent transcriptional repression during Arabidopsis embryogenesis. Science 2008, 319, 1384-1386. [CrossRef] [PubMed]

63. Warner, C.A.; Biedrzycki, M.L.; Jacobs, S.S.; Wisser, R.J.; Caplan, J.L.; Sherrier, D.J. An optical clearing technique for plant tissues allowing deep imaging and compatible with fluorescence microscopy. Plant Physiol. 2014, 166, 1684-1687. [CrossRef] [PubMed]

64. Krogan, N.T.; Hogan, K.; Long, J.A. APETALA2 negatively regulates multiple floral organ identity genes in Arabidopsis by recruiting the co-repressor TOPLESS and the histone deacetylase HDA19. Development 2012, 139, 4180-4190. [CrossRef] [PubMed]

65. Cox, J.; Mann, M. MaxQuant enables high peptide identification rates, individualized p.p.b.-range mass accuracies and proteome-wide protein quantification. Nat. Biotechnol. 2008, 26, 1367-1372. [CrossRef] [PubMed]

66. MacLean, B.; Tomazela, D.M.; Shulman, N.; Chambers, M.; Finney, G.L.; Frewen, B.; Kern, R.; Tabb, D.L.; Liebler, D.C.; MacCoss, M.J. Skyline: An open source document editor for creating and analyzing targeted proteomics experiments. Bioinformatics 2010, 26, 966-968. [CrossRef] [PubMed]

67. Vizcaino, J.A.; Csordas, A.; del-Toro, N.; Dianes, J.A.; Griss, J.; Lavidas, I.; Mayer, G.; Perez-Riverol, Y.; Reisinger, F.; Ternent, T.; et al. 2016 update of the PRIDE database and its related tools. Nucleic Acids Res. 2016, 44, D447-D456. [CrossRef] [PubMed]

(C) 2018 by the authors. Licensee MDPI, Basel, Switzerland. This article is an open access article distributed under the terms and conditions of the Creative Commons Attribution (CC BY) license (http:// creativecommons.org/licenses/by/4.0/). 